\title{
Effectiveness of Comprehensive Diabetes Care (CDC) in Diabetic Patients: an Observational Study
}

\author{
Rohit Sane ${ }^{1}$, Rahul Mandole ${ }^{2}$, Gurudatta Anand Amin ${ }^{3}$, Pravin Ghadigaokar ${ }^{4}$, Sneha Paranjape ${ }^{5}$ \\ ${ }^{1}$ Managing director, MD, Madhavbaug Cardiac Hospitals and Clinics, India \\ ${ }^{2} \mathrm{Head}$ of Department of Research \& Development, Madhavbaug Cardiac Clinic and Hospital, Thane, Maharashtra, India \\ ${ }^{3}$ Chief Medical Officer, Madhavbaug Cardiac Clinic and Hospital, Thane, Maharashtra, India \\ ${ }^{4}$ Head Medical Operations, Madhavbaug Cardiac Clinic and Hospital, Thane, Maharashtra, India \\ ${ }^{5}$ Chief Dietitian, Madhavbaug Cardiac Clinic and Hospital, Mumbai, Maharashtra, India
}

Corresponding author: Rahul Mandole; drrahul@madhavbaug.org

Received 13 July 2020;

Accepted 02 August 2020;

Published 14 August 2020

\begin{abstract}
Background: Globally, Diabetes mellitus (DM) is one of the commonest non-communicable disease to contribute to morbidity and mortality. Its prevalence is increasing dramatically in India and worldwide. Comprehensive Diabetes Care (CDC) is a form of Ayurvedic therapy which combines panchkarma and diet management. Aims and objectives: The present study was done to analyze the effectiveness of CDC on glycosylated haemoglobin (HbA1c), body mass index (BMI), body weight, abdominal girth and dependency on conventional therapy in DM Patients. Materials and methods: This observational study was conducted in July 2018, wherein the data of type 2 DM patients (HbA1c >6.5\%) who attended out-patient departments (OPDs) at Madhavbaug clinics across India were identified. Data of patients who were administered CDC (60-75 minutes) with minimum 6 sittings over 12 weeks were considered. All the glycemic parameters were compared at baseline and week 12 . Results: Out of 1718 type 2 diabetic patients, 893 were males (52\%), while 825 were females (48\%), thus male: female ratio was 1.08:1. CDC showed significant improvement in HbA1c $1.64 \%$ (from $8.64 \pm 0.93$ to $7.00 \pm 1.73$; p<0.001), BMI by 1.68 (from $27.35 \pm 1.34$ to $25.67 \pm 1.06$, $\mathrm{p}=0.04$ ), weight by $4.37 \mathrm{~kg}$ (from $70.71 \pm 11.28$ to $66.37 \pm 12.27, \mathrm{p}=0.05$ ). Abdominal girth (from $95.48 \pm 9.74$ to $90.17 \pm 11.93 ; \mathrm{p}=0.01$ ), also showed significant reduction. At the end of week 12 controlled DM status was seen in 1025 patients. Dependency on concomitant medicines was significantly reduced. Conclusion: Form the findings of present study, CDC has been found to be effective owing to its dual action i.e. reduction in $\mathrm{HbA1c}$ and dependency on conventional antidiabetic drugs.
\end{abstract}

Keywords: Comprehensive Diabetes Care, CDC, panchkarma, glycosylated HB, HbA1C, BMI, DM, alternative medicine.

\section{Introduction}

Globally, type -2 diabetes mellitus (T2DM) is becoming one of the commonest cause of increased morbidity and mortality. This hold true in India also, wherein it stands 2 nd in the world in terms of prevalence rates. It has been projected that the global population will witness massive rise in number of diabetic patients by almost 200 million by the year $2030^{[1]}$. India is estimated to be harboring $10 \%$ of total diabetic patients of the world ${ }^{[2]}$.

Conventionally, diabetes mellitus (DM) is diagnosed by oral glucose tolerance test, wherein fasting blood sugar (FBS) levels $>126 \mathrm{mg} / \mathrm{dl}$ and postprandial blood sugar (PPBS) level of $>140 \mathrm{mg} / \mathrm{dl}$ are indicative of DM. But, recently diabetes is being increasingly diagnosed with measurement of glycosylated hemoglobin (HbA1c) in the blood. This preference for HbA1c is due to the fact that it reflects blood glucose regulation over the preceding 2 months. Cut off values for normal HbA1c have been globally considered to be $<5.7 \%$, while values falling in the range of 5.8 to 6.5 are considered prediabetes and $>6.5 \%$ is diagnostic of diabetes. Thus, target of any antidiabetic therapy is to achieve and maintain $\mathrm{HbA} 1 \mathrm{c}<6.5 \%{ }^{[3]}$.

$\mathrm{DM}$ is associated with numerous complications, which are broadly classified as microvascular and macrovascular complications. Microvascular complications include nephropathy, neuropathy and retinopathy, while macrovascular complications comprises of myocardial infarction, stroke, peripheral vascular disease like claudication, etc. Amongst these, nephropathy and cardiovascular complications are commonest cause of morbidity and mortality in diabetic patients. Apart from these lower limb amputation, diabetic foot ulcer are also common complications of $\mathrm{DM}^{[4]}$.

Conventionally, DM is initially managed by lifestyle changes like regular exercise, dietary corrections. When these interventions are unable to control $\mathrm{HbA} 1 \mathrm{c}<6.5 \%$ after couple of months, then it is advisable to institute oral hypoglycemic drugs (OHDs). Augmenting tissue uptake of glucose, increase in GLUT4 
receptors, increasing excretion of glucose are commonest mechanism of OHDs, which include biguanides like metformin, thiazolidinediones like pioglitazone, sulphonylureas like glimepiride ${ }^{[5]}$. It is recommended that if the HbAlc at baseline is too high or if it is persistently above $7.5 \%$ despite therapy with 1 $\mathrm{OHD}$, then initiate therapy with 2 OHDs with different mechanism of action ${ }^{[5]}$.

OHDs are associated with numerous adverse effects like hypoglycemia, anemia, which not only reduces patient adherence to therapy, but also increases the cost of therapy ${ }^{[6]}$. Despite availability of numerous class of OADs and extensively laid down guidelines, number of cases of DM are consistently increasing ${ }^{[6]}$. Thus, an effective alternative therapy is needed, that will counteract these adverse effects of conventional medicines and increase patient adherence to medications for optimal outcome.

Major aim of any antidiabetic therapy is to reduce the blood sugar levels, so that they fall in optimal range. Various herbal drugs have shown similar effect in clinical studies, including significant reduction in HbA1c ${ }^{[7,8,9]}$. These findings suggest Ayurvedic therapy to be a strong therapeutic modality for treatment of DM. Major form of Ayurvedic therapy is in the form of panchkarma- a multi-step body detoxification process in the chronic phase of disease. Panchkarma and diet therapy is combined in comprehensive diabetes care (CDC) management program. Three techniques are used in panchkarma in CDC- Snehana i.e. oleation, Swedana i.e. passive heat therapy and Basti i.e. medicated enema administered through per rectal route. Panchkarma is well known procedure for internal detoxification of body ${ }^{[10,11]}$. Since DM is associated with reduction in quality of life, depression we planned this retrospective study in patients of type $2 \mathrm{DM}$ across 207 centers from 5 states of India including Maharashtra, Goa, Gujarat, Uttar Pradesh, Karnataka, to assess the efficacy of CDC on various parameters like $\mathrm{HbA1c}$, BMI, reduction in body weight, abdominal girth and reduction in dependency on conventional medications after completion of CDC.

\section{Materials and Methods}

1. Study design: Retrospective record based study.

2. Study site: Madhavbaug clinics across India.

3. Study period: Jan 2019 to Feb 2020

4. Study participants: Patients suffering from type $2 \mathrm{DM}$ $(\mathrm{HbA} 1 \mathrm{c}>6.5 \%),{ }^{[3]}$ who attended Madhavbaug clinics across India.

Table 1: Study Treatment: Comprehensive Diabetes Care (CDC)

\begin{tabular}{|l|l|l|l|}
\hline Step of CDC & Type of Therapy & Herbs used for therapy & Duration of Therapy \\
\hline Snehana & $\begin{array}{l}\text { Massage or external oleation } \\
\text { (centripetal upper strokes on the body) }\end{array}$ & $\begin{array}{l}100 \mathrm{ml} \text { Azadirechta indica (neem) extract } \\
\text { processed in sesame oil }\end{array}$ & 20 minutes \\
\hline Swedana & Passive heat therapy to the body & $\begin{array}{l}\text { Dashmoola (group of ten herbal roots) with } \\
\text { steam at } \leq 40 \text { degrees Celsius) }\end{array}$ & $\begin{array}{l}15-20 \text { minutes + 3-4 minutes } \\
\text { of relaxation after procedure }\end{array}$ \\
\hline Basti kadha & $\begin{array}{l}\text { Per-rectal drug administration should be } \\
\text { in body for } \geq 15 \text { minutes for maximum } \\
\text { absorption }\end{array}$ & $\begin{array}{l}\text { Mixture of 40\% Gudmaar (Gymnema } \\
\text { sylvestre), 20\% Daruharidra (Berberis aristate) } \\
\text { and 40\% Yashtimadhu (Glycyrrhiza glabra) }\end{array}$ & 10 minutes \\
\hline
\end{tabular}

\section{Statistical analysis}

Data were pooled and coded in Microsoft Excel spreadsheet. Data was expressed in terms of Mean $\pm \mathrm{SD}$. Paired t-test was used to assess the difference between baseline values and 90th day after treatment. Histogram were used to represent the graphs.
5. Sample size: 1718 patients suffering from type 2 diabetes mellitus were included in the present study.

\section{Methodology}

The data of patients who had been administered CDC with minimum 6 and maximum 14 sittings over a span of 90 days $( \pm 15$ days) were considered for the study. These patients were maintained on portion-controlled diet kit of 800 calories intake per day, according to patient medical records. The diet plan consisted of low carbohydrates, moderate proteins, and low fats. Cases were identified, and data was assessed from the records of Madhavbaug clinics in India. The selection was based upon the availability of complete relevant baseline data (day 1 of CDC) and final day data (day 90 of CDC) of the patients. The information about prescribed concomitant medicines, if any, was also noted down. On day 1 of $\mathrm{CDC}$, the patients had undergone HbA1c, weight, BMI, abdominal girth measurements as per guidelines ${ }^{[18]}$. This readings were considered as baseline reading. This process was repeated on day 90 of CDC to calculate change from baseline reading. The BMI for day 1 and day 90 of the patients was calculated by checking the weight and the height from the medical data sheets of patients and using the formula: weight in kilograms/ (height in meters) ${ }^{2}$. The dependency on standard medication was calculated both at baseline and week 12 of CDC as the percentage of patients out of the total enrolled ones who required a conventional allopathic therapeutic agent during the study period of 90 days. Those patients were maintained on a diet plan of 800-1000 calories intake per day, according to patient medical records.

Based on HbA1c levels after CDC therapy the patients were categorized as:

- $\quad$ Controlled- HbA1c $<5.7$

- $\quad$ Borderline- HbA1c 5.7-6.5

- Uncontrolled- $\mathrm{HbA} 1 \mathrm{c}>6.5$

Diet box: Diet box was given to the patients, which was 1 month food packing designed to comply with low carbohydrate and low fat diet with daily calorie intake of 800 calories. 1 diet box was designed for 1 month, therefore number of diet boxes were equivalent to number of months on taking the compliance diet.

The CDC is a 3-step procedure which was performed on the patients of type $2 \mathrm{DM}$ after a light breakfast. One sitting of the procedure took 65-75 minutes, as described in table $1^{[12]}$.

(1)

\section{Results}

In the present study, out of 1718 type 2 diabetic patients, 893 were males (52\%), while 825 were females (48\%), thus male: female ratio was 1.08:1 [Figure 1]. 


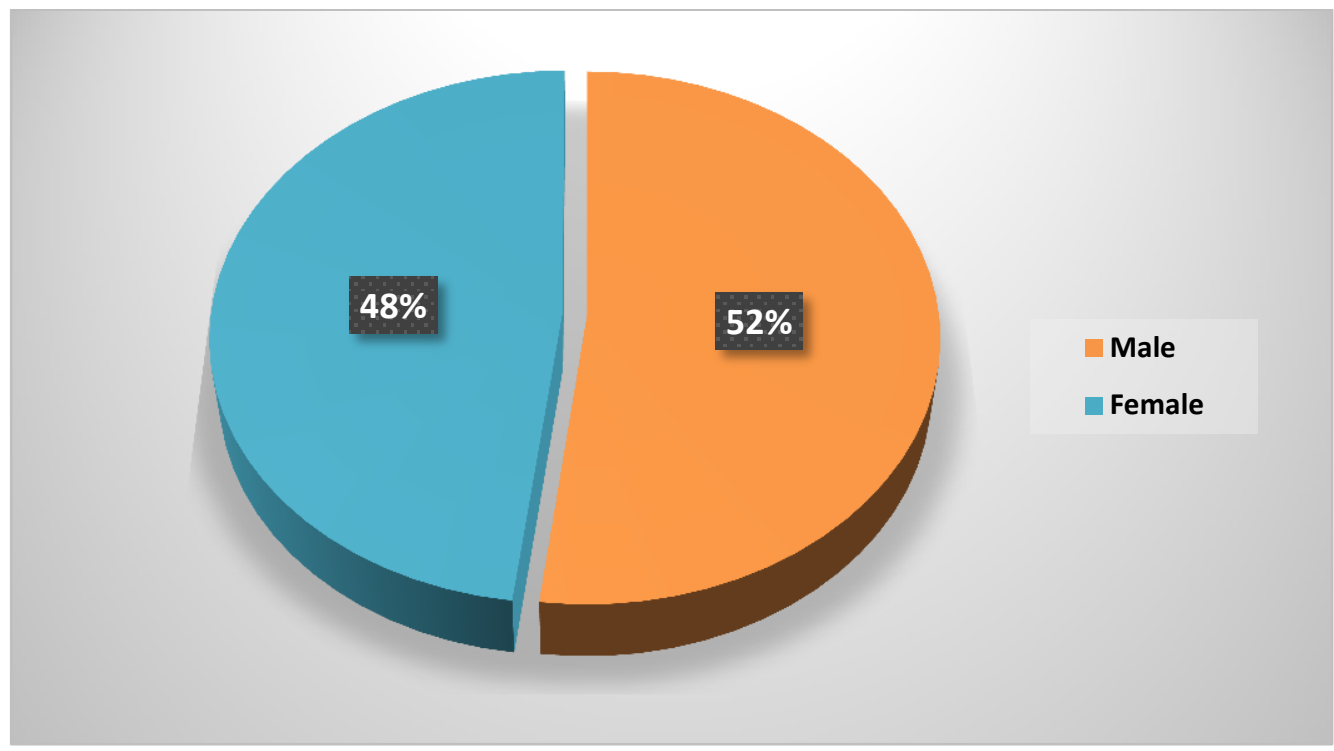

Figure 1: Sex distribution in patients of the present study.

$18 \%$ of the total patients were not given any diet boxes, while 1 $36 \%$ and 4 diet boxes were given to $1 \%$ of the patients [Figure 2]. diet box was given to $22 \%, 2$ diet boxes to $23 \%, 3$ diet boxes to

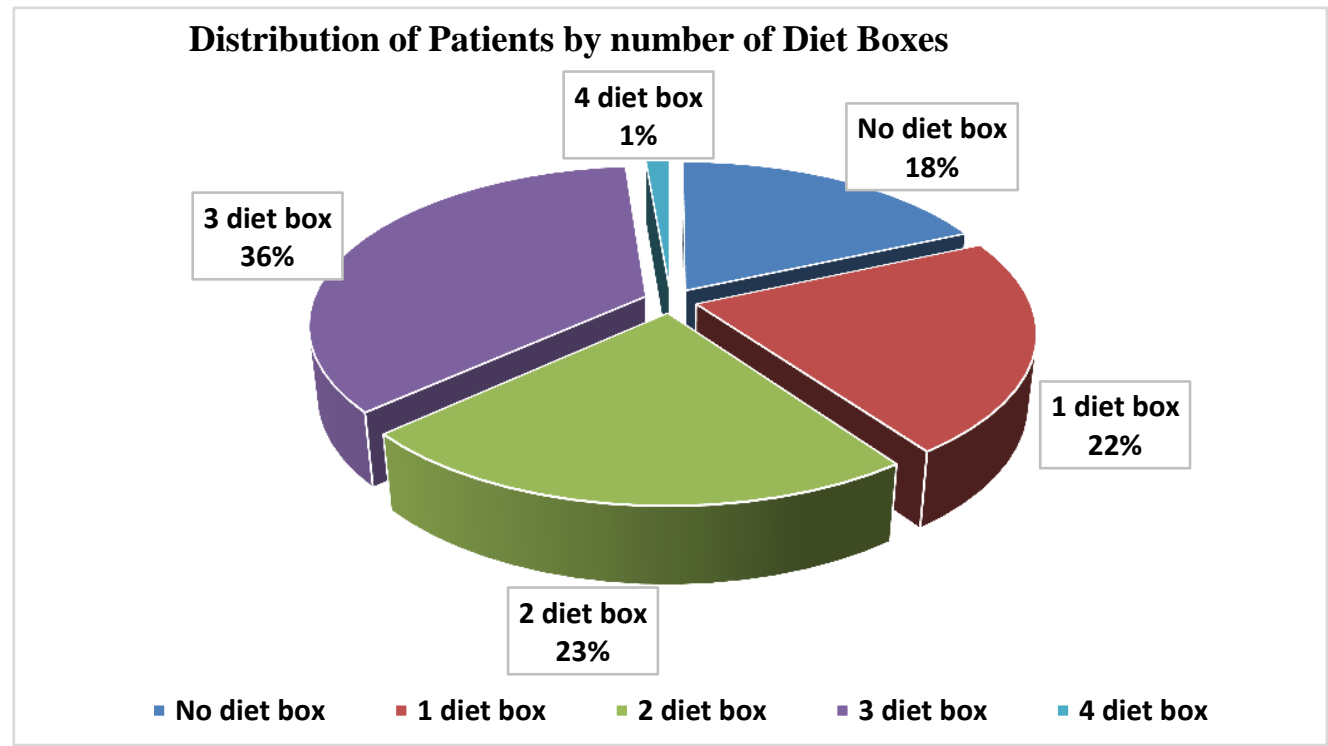

Figure 2: number of diet boxes used by patients of present study.

On analyzing the anthropometric parameters in the patients of present study, it was found that body mass index (BMI) was reduced from $27.35 \pm 1.34 \mathrm{~kg} / \mathrm{m} 2$ at baseline to $25.67 \pm 1.06 \mathrm{~kg} / \mathrm{m} 2$ at the end of 12 weeks of CDC therapy, and this difference was statistically significant $[p=0.04]$. Similarly abdominal girth was reduced from $95.48 \pm 1.8$ at baseline to $90.17 \pm 2.2$ at 12 weeks of
CDC therapy $[p=0.01]$. Similarly cardiopulmonary parameters like systolic blood pressure (SBP), diastolic BP (DBP), VO2 peak showed improvements in reading at 12 weeks of CDC therapy, as compared to baseline and these differences were highly statistically significant. Lipid parameters showed similar trends which can be seen in table 1.

Table 2: anthropometric, cardio-pulmonary and lipid parameters in the patients of present study at baseline and 12 weeks of CDC therapy.

\begin{tabular}{|c|c|c|c|c|c|}
\hline Sr. No. & Parameter & Measurement & Baseline & 12 week & p-value \\
\hline \multirow[t]{3}{*}{1} & \multirow{3}{*}{ Anthropometry } & Weight & $70.71 \pm 6.9$ & $66.37 \pm 5.9$ & 0.05 \\
\hline & & BMI & $27.35 \pm 1.34$ & $25.67 \pm 1.06$ & 0.04 \\
\hline & & $\mathrm{ABG}$ & $95.48 \pm 1.8$ & $90.17 \pm 2.2$ & 0.01 \\
\hline \multirow[t]{3}{*}{2} & \multirow[t]{3}{*}{ Cardio-pulmonary } & SBP & $131.38 \pm 6.7$ & $123.27 \pm 5.12$ & 0.001 \\
\hline & & DBP & $80.75 \pm 4.8$ & $76.77 \pm 4.1$ & 0.001 \\
\hline & & VO2 peak & $22.35 \pm 2.13$ & $25.41 \pm 2.89$ & 0.02 \\
\hline \multirow[t]{4}{*}{3} & \multirow[t]{4}{*}{ Lipid profile } & Cholesterol & $170.32 \pm 4.37$ & $124.34 \pm 3.91$ & 0.000 \\
\hline & & HDL & $36.39 \pm 2.24$ & $42.28 \pm 2.38$ & 0.01 \\
\hline & & LDL & $106.72 \pm 5.12$ & $81.69 \pm 4.71$ & 0.002 \\
\hline & & TG & $195.67 \pm 7.14$ & $113.08 \pm 8.03$ & 0.000 \\
\hline
\end{tabular}


BMI- Body Mass Index, ABG-abdominal girth, SBP-systolic blood pressure, DBP-diastolic blood pressure, HDL- High Density Lipoprotein, LDL- Low Density Lipoprotein, TG-Triglycerides.

On analyzing the results of HbAlc levels in patients at baseline and after completion of 12 week CDC therapy, it was found that normal $\mathrm{HbA} 1 \mathrm{c} /$ controlled status was seen in 1025 patients (59\%) at week 12 as compared to 0 patient at baseline, borderline $\mathrm{HbA1c}$ was seen in 250 patients (14\%) and 767 patients (45\%) at week 12 and baseline respectively, while deranged $\mathrm{HbA1c}$ readings/uncontrolled status was noted in 443 patients (27\%) and 951 patients (55\%) at week 12 and baseline, respectively [Figure 3].

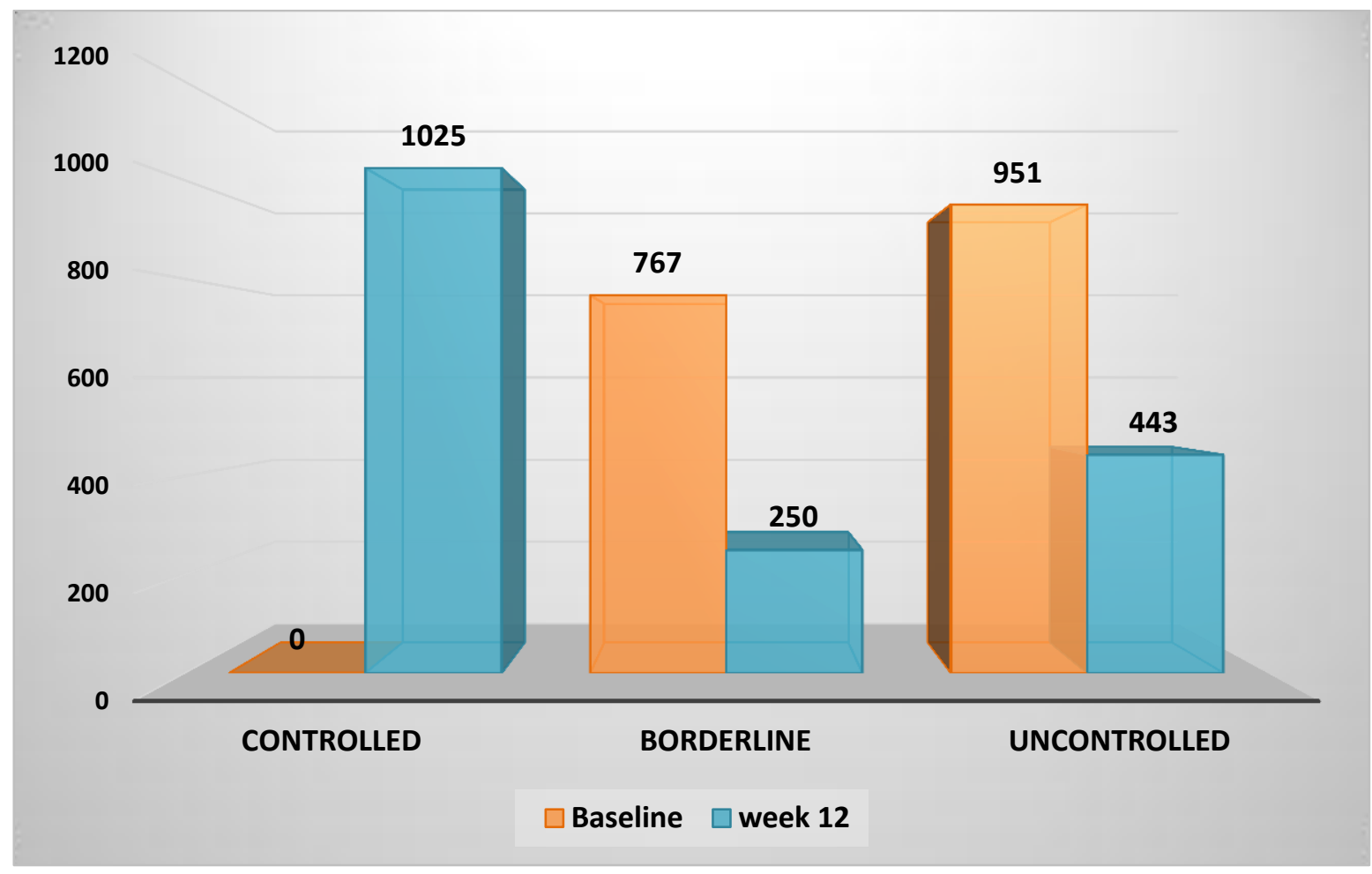

Figure 3: Comparison of results of HbA1c in patients at baseline and after 12 weeks of CDC therapy.

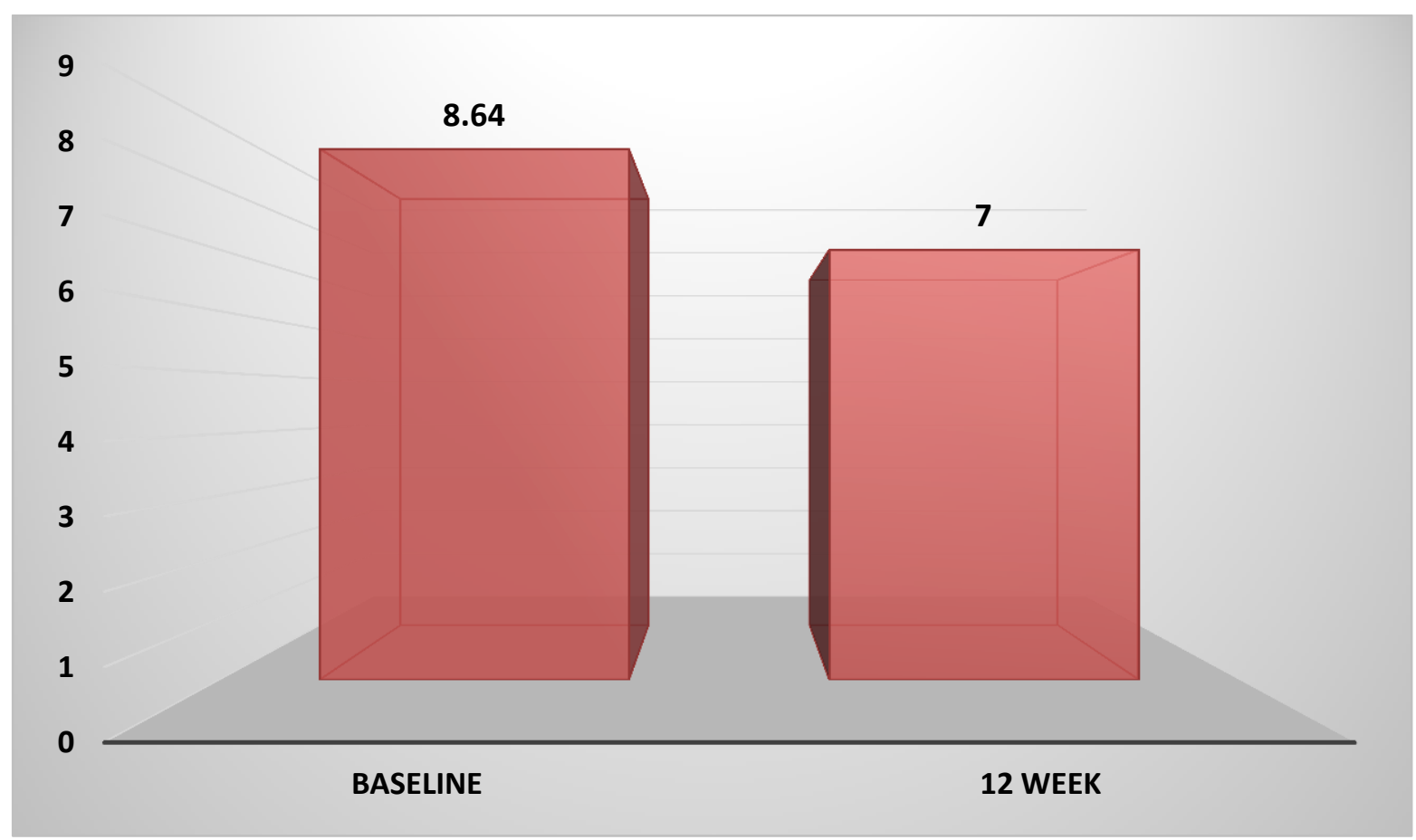

Figure 4: Glycosylated hemoglobin (HbA1c) in patients of present study at baseline and at 12 weeks of taking CDC therapy.

Medication history was available in 1716 patients, out of which majority of the patients were taking biguanides and sulfonylureas (SU). The number of tablets/patient ratio reduced from 2.02 at baseline to 0.87 at week 12 of CDC therapy, thus there was $57 \%$ reduction in number patients taking allopathic medications after 12 weeks of CDC therapy, with major reduction seen in intake of biguanides and SU [Table 3]. 
Table 3: Consumption of allopathic medications by the patients in the present study at baseline and at 12 weeks of CDC therapy

\begin{tabular}{|c|c|c|c|c|}
\hline \multicolumn{5}{|c|}{ No. of patients taking allopathic medicines } \\
\hline Sr. No. & Medication & Baseline & Week 12 & p-value \\
\hline 1 & $\beta$ blocker & 227 & 140 & 0.001 \\
\hline 2 & ARB & 428 & 268 & 0.001 \\
\hline 3 & $\mathrm{CCB}$ & 261 & 146 & 0.001 \\
\hline 4 & Diuretic & 134 & 73 & 0.001 \\
\hline 5 & SU & 750 & 433 & 0.001 \\
\hline 6 & Biguanides & 1001 & 245 & 0.001 \\
\hline 7 & Antiplatelet & 155 & 77 & 0.02 \\
\hline 8 & DPP4 inhibitor & 224 & 53 & 0.001 \\
\hline 9 & Statins & 301 & 69 & 0.001 \\
\hline 10 & Tablet/patient ratio & 2.02 & 0.87 & 0.001 \\
\hline
\end{tabular}

ARB-angiotensin receptor blocker, CCB-calcium channel blocker, SU-sulfonylurea, DPP4- dipeptidyl peptidase

On analyzing HbA1c status at end of week 12 of CDC therapy, it was found that number of patients with controlled DM status increased and that with uncontrolled status reduced at week 12. The greatest changes were observed in patients with duration of DM > 10 years. [Table 4].

Table 4: HbA1c results at baseline and week 12 of CDC therapy with respect to duration of DM.

\begin{tabular}{|c|c|c|c|c|c|}
\hline \multirow{2}{*}{ Duration of DM } & \multirow{2}{*}{ Period of CDC therapy } & \multicolumn{3}{|c|}{ HbA1c status } & \multirow{2}{*}{$\mathbf{N}$} \\
\hline & & Controlled & Borderline & Uncontrolled & \\
\hline \multirow{2}{*}{$<2 \mathrm{yrs}$} & Baseline & 0 & 200 & 131 & 331 \\
\hline & week 12 & 146 & 50 & 135 & 331 \\
\hline \multirow{2}{*}{$2-10$ yrs } & Baseline & 0 & 228 & 296 & 524 \\
\hline & week 12 & 312 & 91 & 121 & 524 \\
\hline \multirow{2}{*}{$>10 \mathrm{yrs}$} & Baseline & 0 & 339 & 524 & 863 \\
\hline & week 12 & 567 & 109 & 187 & 863 \\
\hline
\end{tabular}

\section{Discussion}

The prevalence of type 2 diabetes mellitus is increasing continuously throughout the world and has emerged as one of the commonest culprit of morbidity and mortality. This becomes more worrisome when we already have huge armamentarium of conventional drugs therapy available to control disease. Thus, it becomes imperative to search and validate other viable treatment alternatives which will aid in curtailing the havoc caused by type 2 diabetes mellitus. Major action of traditional oral hypoglycemic drugs is to reduce the elevated blood glucose levels towards optimal range. Variety of herbal drugs have been found to have similar actions on blood sugar levels, and thus Ayurvedic form of medicine can serve as most potent alternative in management of type 2 diabetes mellitus. Panchkarma is the commonest Ayurvedic therapy given to the patient so type 2 diabetes mellitus ${ }^{[10]}$. CDC combines Panchkarma diet regimen consisting of low levels of carbohydrates and fats and modest amount of proteins.

The mechanisms, by which CDC is thought to deliver beneficial actions in patients of type 2 diabetes mellitus are as follows:

- Attenuating the synthesis of glucose by inhibiting the process of gluconeogenesis via inhibiting sympathetic system.

- Decreasing the wear off of vascular endothelium via increasing loss of water through sweating ${ }^{[10]}$.

BMI, body weight, abdominal girth were significantly reduced in the present study at the end of 12 weeks. Similarly, most critical parameter in type 2 diabetes i.e. glycosylated hemoglobin was also significantly reduced after CDC therapy. Also, the number of patients allopathic medications reduced drastically at the end of 12 weeks, which means that dependency on conventional medications was significantly reduced after CDC therapy.

As stated earlier, $\mathrm{HbA1c}$ is most critical parameter in type 2 diabetics as it reflects blood glucose control over preceding 2 months.13 Apart from this, its role as prognostic indicator of morbidity and mortality is well established in literature and is universally accepted, as sustained increased levels are associated with bad prognosis.14 Keeping these published evidences in mind, it can be deducted from findings of the present study that CDC is anticipated to improve the prognosis in patients of type $2 \mathrm{DM}$ as it significantly reduced $\mathrm{HbA} 1 \mathrm{c}$ levels at week 12 .

Also, in the present study it was found that optimal changes in number of patients with controlled DM status was greatest in those with duration $>10$ years, wherein the glycemic control is usually more deranged.

In terms of complications, most dreaded complication of DM are cardiovascular ones, which are a major cause of morbidity and mortality in these patients. In a landmark clinical trial ACCORD, the effect of intensified glycemic control therapeutic regimen (targeting $\mathrm{HbA} 1 \mathrm{c}<6 \%$ ) was compared to usual glycemic control regimen (targeting $\mathrm{HbA1c} 7-7.9 \%$ ) in terms of cardiovascular mortality outcomes ${ }^{[15,16]}$. They found that intense glycemic control regimen actually increased cardiovascular mortality by 3.5 times as compared to the usual regimen. 17 This means that aim of HbA1c reduction should not be brisk, which is usually happens with conventional OADs. Thus, any alternate therapy which is able to reduce HbA1c gradually within optimal range and same time reduce the dependency on conventional OADs might actually help to improve outcomes in terms of cardiovascular after effects.

Lack of physical activity and obesity are implicated to be the major factor responsible for development and amplification of insulin resistance, a hallmark of type $2 \mathrm{DM}^{[18]}$. Increased BMI is also found to be associated with increased risk of developing 
cardiovascular diseases like hypertension, coronary artery disease, etc ${ }_{[19]}$. Glycemic variability is considered to be the most critical factor in development of complications and thus poor prognosis in type $2 \mathrm{DM}^{[20]}$. Thus, constant optimization of blood glucose levels i.e. less glycemic variability is important in these patients. In this regards, $\mathrm{CDC}$ might aid in reducing the risk of complications owing to its maintained reduction in $\mathrm{HbA1c}$, body weight, etc.

One of the major challenge with conventional oral antidiabetic drug therapy is frequent adverse effects and amplified cost of therapy, all of which reduce the patient compliance/ adherence to treatment ${ }^{[21]}$. In the present study, number of patients taking conventional drug therapy reduced drastically at the end of study period, which means that dependency of conventional drugs was reduced in patients after CDC therapy.

However, we recommend that such studies should be carried out prospectively at multiple centers all over India, which aid in comparison and validation of current study findings.

\section{Conclusion}

CDC reduced glycosylated hemoglobin, body mass index, abdominal girth and also the patient's dependency on conventional medications. Thus, it can be concluded that CDC will not only serve as effective option to manage type $2 \mathrm{DM}$, but it will also improve the prognosis, as well as patient compliance.

\section{Source of funding}

Not applicable.

\section{Conflicts of interest}

None declared by the authors.

\section{References}

[1] Unwin N, Whiting D, Guariguata L, Ghyoot G, Gan D (Eds). The IDF Diabetes Atlas, 5th edition. Brussels, Belgium: International Diabetes Federation; 2011.pp.712.

[2] Kaveeshwar S, Cornwall J. The current state of diabetes mellitus in India. Australas Med J. 2014; 7(1): 45-48.

[3] Verma M, Paneri S, Badi P, et al. Effect of increasing duration of diabetes mellitus type 2 on glycated hemoglobin and insulin sensitivity. Indian Journal of Clinical Biochemistry, 2006, 21 (1): 142-146.

[4] Forbes JM, Cooper ME. Mechanisms of Diabetic Complications. Physiol Rev. 2013; 93:137-188.

[5] Matthaei S, Bierwirth R, Fritsche A, et al. Medical Antihyperglycaemic Treatment of Type 2 Diabetes Mellitus. Exp Clin Endocrinol Diabetes 2009; 117: 522 557.

[6] Edelman S. Current issues in the management of type 2 diabetes mellitus. Consultant 2009:S3.
[7] Elder C, Aickin M, Bauer V et al. Randomized Trial of a Whole-System Ayurvedic Protocol for Type 2 Diabetes. Alternative Therapies in Health and Medicine. 2006;12(5): 24-30.

[8] Vidyashree K, Prasad K, Shilpa A. Role of Panchkarma in madhumeha w.s.r. to type 2 diabetes mellitus: a review. International Ayurvedic Journal. 2018; 6(4): 835840.

[9] Choudhary U, Pandey A. A clinical assessment of the role of panchakarma therapy in the care of young prediabetics. International Journal of General Medicine and Pharmacy. 2013; 2(1): 15-24.

[10] Giri S, Patnaik S, Kumar K, et al. Potential of ayurvedic panchakarma in prevention and management of lifestyle disorders with special reference to madhumeha, $\mathrm{J}$ of Ayurveda and Hol Med (JAHM). 2015;3(5):82-91

[11] Nair D. Understanding the Role of Ayurveda Panchakarma Therapy W.S.R. to Vasthi (Enema) in the Management of Type II Diabetes Mellitus- A Case Review. Int J Complement Alt Med. 2017; 8(6): 00276.

[12] Sane R, Sabir I, Naik M, et al. Comprehensive Diabetes Care (CDC) Management Program in Type II Diabetic Obese Patients. International Journal of Ayurveda and Pharma Research. 2018; 6(6):6-12.

[13] Sherwani S, Khan H, Ekhzaimy A, et al. Significance of HbA1c Test in Diagnosis and Prognosis of Diabetic Patients. Biomarker Insights 2016:11 95-104.

[14] Sarmah D, Sharma B. Importance and Status of HBA1C in T2DM and its Indian Perspective. Asian Journal of Biomedical and Pharmaceutical Sciences 2012; 2(12): 01-10.

[15] Buse J, Bigger J, Byington R, et al. Action to Control Cardiovascular Risk in Diabetes (ACCORD) trial: design and methods. Am J Cardiol. 2007; 99(12A):21i-33i.

[16] Gerstein H, Riddle M, Kendall D, et al. Glycemia treatment strategies in the Action to Control Cardiovascular Risk in Diabetes (ACCORD) trial. Am J Cardiol. 2007; 99(12A):34i-43i.

[17] Gerstein H, Miller M, Byington R, et al. Effects of intensive glucose lowering in type 2 diabetes. $\mathrm{N}$ Engl $\mathrm{J}$ Med. 2008;358(24):2545-59.

[18] Bertoglia M, Gormaz J, Libuy M, et al. The population impact of obesity, sedentary lifestyle, and tobacco and alcohol consumption on the prevalence of type 2 diabetes: Analysis of a health population survey in Chile, 2010. PLoS ONE 2017; 12(5): e0178092.

[19] Csige I, Ujvárosy D, Szabó Z, et al. The Impact of Obesity on the Cardiovascular System. J Diabetes Res. 2018; 2018:3407306.

[20] Kovatchev B, Cobllo C. Glucose Variability: Timing, Risk Analysis, and Relationship to Hypoglycemia in Diabetes. Diabetes Care 2016; 39:502-510.

[21] Perwitasari D, Urbayatun S. Treatment Adherence and Quality of Life in Diabetes Mellitus Patients in Indonesia. Sage Open. 2016:1-7. 